J. Dairy Sci. 92:540-547

doi:10.3168/jds.2008-1424

(C) American Dairy Science Association, 2009.

\title{
The impact of meloxicam on postsurgical stress associated with cautery dehorning
}

\author{
A. Heinrich, ${ }^{*}$ T. F. Duffield, ${ }^{*}$ K. D. Lissemore, ${ }^{*}$ E. J. Squires, $\dagger$ and S. T. Millman ${ }^{\star} \neq^{1}$ \\ *Department of Population Medicine, Ontario Veterinary College, University of Guelph, Guelph, Ontario, Canada \\ †Department of Animal and Poultry Science, University of Guelph, Guelph, Ontario, Canada \\ $\ddagger$ Veterinary Diagnostic and Animal Production Medicine, Biomedical Sciences, lowa State University, Ames 50011
}

\section{ABSTRACT}

The objectives were to determine the duration of the stress response associated with cautery dehorning and to assess the effectiveness of the nonsteroidal antiinflammatory drug meloxicam (Metacam, $20 \mathrm{mg} / \mathrm{mL}$ solution for injection) for reducing that response. Sixty Holstein heifer calves were blocked by age and randomly assigned to receive an i.m. injection of meloxicam or a placebo $(0.5 \mathrm{mg} / \mathrm{kg})$. All calves were given a lidocaine cornual nerve block delivered $5 \mathrm{~mL}$ per side $10 \mathrm{~min}$ before dehorning. To establish baseline values, calves were sham dehorned $24 \mathrm{~h}$ before actual dehorning. Blood samples were taken via indwelling jugular catheters at $0,0.5,1,1.5,2,4,6$, and $24 \mathrm{~h}$ after the procedure. Heart and respiratory rates were also taken at these times. Data were analyzed using PROC MIXED in SAS. Analysis of covariance was employed to assess the difference between sham and dehorning at each time period. Dehorning was associated with elevated serum cortisol $(\mathrm{d}-1: 33.9 \pm 1.26 ; \mathrm{d}$ 0: $46.2 \pm 2.33 \mathrm{nmol} / \mathrm{L})$ and heart rate $(\mathrm{d}-1: 108 \pm 1.8 ; \mathrm{d}$ 0: $109.4 \pm 2.4$ beats per minute) in both groups for $24 \mathrm{~h}$, and elevated respiratory rate (sham: $42.2 \pm 1.95$ vs. dehorning: 45.1 \pm 2.19 respirations per minute) in both groups for $6 \mathrm{~h}$. A treatment $\times$ time interaction was found for cortisol, with meloxicam calves having lower serum cortisol than controls until $6 \mathrm{~h}$ after dehorning (meloxicam: $49.7 \pm$ 4.37 vs. control: $63.0 \pm 6.94 \mathrm{nmol} / \mathrm{L}$ ). There was no difference between the treatment groups at $24 \mathrm{~h}$ (meloxicam: $35.2 \pm 2.74$ and control: $34.8 \pm 3.64 \mathrm{nmol} / \mathrm{L}$ of cortisol). Overall, the changes in heart rates (increase meloxicam: $3.74 \pm 0.96$ vs. control: $4.70 \pm 1.87)$ and respiratory rates (increase meloxicam: $2 \pm 0.1$ vs. control: $4 \pm 0.2$ ) were greater in the control group compared with the meloxicam group. These results indicate that meloxicam reduced the physiological stress response to dehorning.

Key words: dehorning, disbudding, meloxicam, pain

Received June 4, 2008.

Accepted October 15, 2008

${ }^{1}$ Corresponding author: smillman@iastate.edu

\section{INTRODUCTION}

Dehorning is a painful procedure that is commonly performed on dairy calves to prevent injury to stockpeople and other cattle. Dehorning refers to amputation of horns in mature cattle or removal of the horn buds of calves; the latter is also referred to as disbudding. Dehorning causes an initial rapid peak in plasma cortisol, corresponding to the acute pain of tissue damage and animal handling, which declines to a plateau level for approximately 7 to $9 \mathrm{~h}$ before returning to baseline levels, indicating the presence of an inflammatory response (Stafford and Mellor, 2005). A rise in cortisol concentration represents a stress response due to activation of the hypothalamic-pituitary adrenal axis and is not directly indicative of pain (Weary et al., 2006). Nevertheless, cortisol is a useful measure of stress associated with painful procedures such as castration of calves (Thüer et al., 2007) and lambs (Mellema et al., 2006), mulesing of lambs (Paull et al., 2007), and velvet antler removal in cervids (Woodbury et al., 2002) and continues to be a common component of pain assessment.

Acute pain caused by dehorning can be alleviated using a local anesthetic. Local anesthetic decreased cortisol (McMeekan et al., 1998b; Graf and Senn, 1999; Milligan et al., 2004) and behavioral (McMeekan et al., 1999; Sylvester et al., 2004) responses to dehorning, as well as eliminating the acute drop in eye temperature (Stewart et al., 2008), increase in heart rate (GrøndahlNielsen et al., 1999; Stewart et al., 2008), and changes in electroencephalogram (Gibson et al., 2007) associated with the procedure.

Most local anesthetics last approximately $2 \mathrm{~h}$, but evidence of pain has been described for 8 to $24 \mathrm{~h}$ after local anesthetic regimes (McMeekan et al., 1998a; Faulkner and Weary 2000). As a result, nonsteroidal anti-inflammatory drugs (NSAID) were the subject of recent research into dehorning pain. Phenylbutazone did not reduce maximum cortisol concentration (Sutherland et al., 2002), whereas ketoprofen reduced the delayed peak in cortisol that commonly correlates with the end of the duration of action of local anes- 
thetics (McMeekan et al., 1998b; Milligan et al., 2004). Nonetheless, because the half life of ketoprofen is short, one injection may not provide sufficient postsurgical analgesia for dehorning. Stafford et al. (2003) detected a significant rise in plasma cortisol $4 \mathrm{~h}$ postdehorning when calves were given ketoprofen and local anesthetic before dehorning. Similarly, ketoprofen was effective for reducing the stress response for $5 \mathrm{~h}$ after dehorning, but plasma cortisol was elevated above pretreatment levels from 5 to $11 \mathrm{~h}$ postdehorning (Sutherland et al., 2002).

Meloxicam is an NSAID with preferential cyclooxygenase- 2 activity and a half life of approximately $26 \mathrm{~h}$ in bovine plasma (EMEA, 2007; p. 8). Because the half life of ketoprofen is approximately 2 to $4 \mathrm{~h}$ in calves (Landoni et al., 1995), meloxicam is expected to provide a more appropriate length pain relief with 1 injection. Also, the preferential cyclooxygenase-2 activity of meloxicam is likely more gentle on the gastrointestinal system and on the developing rumen of the calf (Plumb, 2002). A single injection of meloxicam has a longer halflife than flunixin meglumine (Odensvik and Johansson, 1995), which is the NSAID currently approved for use in cattle in the United States.

The objectives were to 1 ) determine the duration of the physiological response to cautery dehorning with a local anesthetic and 2) to test the efficacy of meloxicam at reducing that response by relieving pain and inflammation.

\section{MATERIALS AND METHODS}

\section{Animals and Housing}

The study was conducted at the Elora Dairy Research Centre of the University of Guelph (Ontario, Canada) between September 2005 and July 2006. Sixty Holstein heifer calves, ranging in age from 6 to $12 \mathrm{wk}$, were housed individually in pens measuring $48 \times 60$ inches $(1.3 \times 1.5 \mathrm{~m})$, separated by partitions allowing visual and tactile contact through vertical bars. The same pens were used in all trials. Calf starter (Floradale Feed Mill, 20\% calf starter with lasalocid, Elora, Ontario, Canada) was offered ad libitum from birth and became the sole feed after weaning. Weaning took place at 6 wk of age, before the calves were enrolled in the trial. Throughout the trial, calves were offered $3 \mathrm{~kg}$ of starter twice daily. The nursery was lit from 0545 until $2045 \mathrm{~h}$, and a single $100-\mathrm{W}$ bulb was hung in the middle of the nursery to facilitate overnight behavioral observations (Heinrich, 2007). Temperature was maintained at $8^{\circ} \mathrm{C}$ in the winter but varied with outside temperature in the spring and summer (Figure 1). Calves were weighed on the morning before they were enrolled in the trial, and mean BW of calves was $88.8 \pm 1.95 \mathrm{~kg}$.

\section{Experimental Design and Treatments}

This experiment was a randomized complete block design. It was conducted using groups of 2 or 4 calves over a total of 17 trials. Trials consisted of 1 or 2 complete replicates. Before each trial began, calves were blocked by age and randomly assigned to meloxicam or control treatments. Meloxicam calves $(\mathrm{n}=30)$ received a single i.m. injection of meloxicam (Metacam, $20 \mathrm{mg} / \mathrm{mL}$ solution for injection, Boehringer Ingelheim, Vetmedica, Ingelheim, Germany) at a dose of $0.5 \mathrm{mg} /$ $\mathrm{kg}$ of BW. Control calves $(\mathrm{n}=30)$ received a single i.m. injection of the vehicle with meloxicam removed. To control for pen effects, calf pens were assigned to alternate treatments and treatments were reversed for each trial.

On the first day of the trial $(\mathrm{d}-1)$, 16-gauge catheters (Angiocath, Becton Dickinson Canada, Oakville, Ontario, Canada) were inserted into the left jugular vein of each calf at $0730 \mathrm{~h}$. This was $2 \mathrm{~h}$ before sampling began and so any cortisol response to catheter insertion would have normalized before sampling. Catheters were sutured in place and bandaged to prevent calves from removing them. At $0930 \mathrm{~h}$, calves were sham dehorned using an unheated electric cautery iron (Rhinehart X30, Rhinehart Development Corporation, Spencerville, IN). On d 0, treatments and cornual nerve blocks ( $2 \%$ lidocaine $\mathrm{HCl}$ with $0.05 \mathrm{mg} / \mathrm{mL}$ of epinephrine, BimedaMTC, Cambridge, Ontario, Canada) were administered $10 \mathrm{~min}$ before dehorning. Five milliliters of lidocaine were administered per horn. The iron was preheated for at least $10 \mathrm{~min}$ to a temperature of approximately $600^{\circ} \mathrm{C}$, and calves were dehorned by cauterization. Injections and dehorning were always performed by the same veterinary technician, and restraint, sham dehorning, and data collection were performed by the same researcher. To control for possible bias, all personnel were blind to treatments.

All procedures were approved by the Animal Care Committee of the University of Guelph.

\section{Data Collection}

Immediately after sham and actual dehorning $(0 \mathrm{~h})$ and again at $0.5,1,1.5,2,4,6$, and $24 \mathrm{~h}$, heart and respiratory rates were taken and a blood sample was obtained. Ambient temperature was recorded at each sampling. Respiratory rates at $0 \mathrm{~h}$ were taken immediately after dehorning or sham procedure when calves were restrained; all other respiratory rates were taken from outside the pen to minimize effect of handling. Respiratory rate was determined by counting the flank movements of the calf for $15 \mathrm{~s}$ and converting to respirations per minute (rpm). 


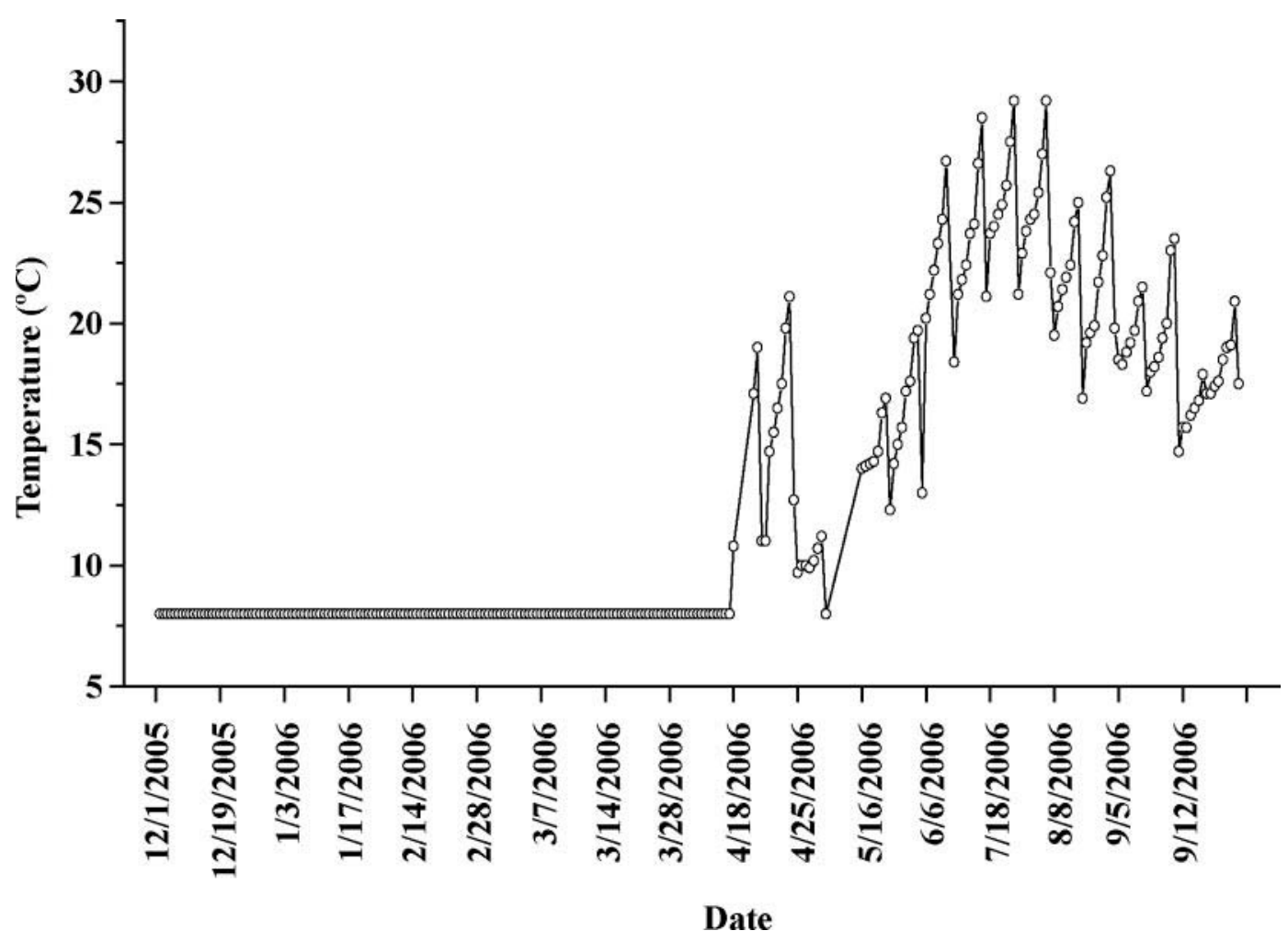

Figure 1. Temperature of the calf nursery at each of the sampling times on each trial. Temperature was maintained at $8^{\circ} \mathrm{C}$ during the winter months, but varied with outside temperature during spring and summer $(P<0.001)$.

Calves were haltered and tied for blood sampling and then heart rate. Before sampling $5 \mathrm{~mL}$ of blood was drawn from the catheter and discarded to prevent dilution by heparin. Ten milliliters of blood was then taken from the catheter and transferred to 10-mL glass tubes without anticoagulant (Vacutainers, Becton Dickinson Canada). Following blood sampling, catheters were filled with $10 \mathrm{~mL}$ of saline containing $0.01 \%$ heparin to prevent clotting. Blood was stored at $4^{\circ} \mathrm{C}$ overnight and then centrifuged at 1,400 $\times \mathrm{g}$. Serum was harvested and frozen at $-70^{\circ} \mathrm{C}$ until assayed. Heart rates were determined manually by listening to the heart with a stethoscope, counting beats for $15 \mathrm{~s}$ and converting to beats per minute (bpm).

\section{Cortisol Analysis}

The concentration of cortisol in serum was determined using RIA kits (Coat-A-Count, Diagnostic Products Corporation, Los Angeles, CA). The kits were validated for use with bovine blood by testing for parallelism against the human standards provided in the kit. Because most of the bovine samples contained a low concentration of cortisol, dilutions of the human standards were prepared to expand the bottom range of the curve (Battaglia et al., 1997). The test for parallelism was satisfied as the slope of the line for human standards did not differ from that of the set of prepared bovine dilutions. The mean intra- and interassay coefficients of variation were 5.9 and $19.6 \%$, respectively. To control for low interassay precision, 2 bovine control samples of known concentration were assayed with each batch of trial samples. Each trial sample was then corrected for the amount of variation in control samples by subtracting the average of the deviation in the control samples from the trial sample. All samples were assayed in duplicate and counted for $1 \mathrm{~min}$ in a gamma counter (LKB Model 1274, LKB Instruments, Rockville, MD). Samples were reassayed if there were subjectively large discrepancies between the duplicates. Cortisol concentration was expressed in nanomoles per liter of serum.

\section{Statistical Analysis}

Data were analyzed using the SAS program (version 9.1.3; SAS Institute Inc., Cary, NC). Analyses of covariance were performed using PROC MIXED, with measurements taken after the sham procedure as covariates to determine the difference between sham and actual dehorning. PROC UNIVARIATE was used 
to visually assess distribution of the data; transformations were applied to achieve normality. Cortisol data required a quarter root transformation, whereas a log transformation was sufficient for heart and respiratory rates. There was a random effect of trial and repeated measures on calf (nested within trial and treatment) included in the model. The autocorrelation structure with the lowest Akaike's information criterion value was used for the repeated measures analyses. Main effects (time, treatment, covariate, age, days since weaning, temperature, and weight) and their interactions were tested, and effects with $P>0.1$ were eliminated from the model using backward elimination. To adjust for multiple comparisons of treatment at each time period, a 1-tailed multivariate $t$-test was used. Tukey's test for pair-wise comparisons was used to examine the effect of time within each treatment group. A $P$-value of $<0.05$ was considered significant.

\section{RESULTS}

There were no differences in respiratory rate $(P=$ $0.9)$ or serum cortisol concentration $(P=0.63)$ between groups after sham dehorning $(\mathrm{d}-1)$. Despite randomization and blocking, there was a difference in mean heart rate between the treatment groups on $\mathrm{d}-1(P=$ 0.04). Calves assigned to receive meloxicam had lower heart rates.

Respiratory rates were elevated in both groups in both groups above baseline for $6 \mathrm{~h}$ (mean $\pm \mathrm{SE}$ were $\mathrm{d}$ $-1=42.2 \pm 1.95 \mathrm{rpm}, \mathrm{d} 0=45.1 \pm 2.19 \mathrm{rpm}, P=0.02)$ and had returned to baseline by $24 \mathrm{~h}$. Mean change in respiratory rate from baseline is provided in Figure 2. Overall, calves had higher respiratory rates after dehorning compared with sham treatment; however, the increase was greater for control calves (average increase of $2 \pm 0.1$ and $4 \pm 0.2 \mathrm{rpm}$ for meloxicam and control, respectively, $P<0.001$ ). The effect of treatment over time was not significant. Respiratory rate was affected by environmental temperature $(P<0.001)$. Because temperature in the nursery was not constant (Figure 1 ), its effect was confounded with day and hour during trials conducted in warmer months. Yet, these effects were balanced for treatment groups.

Some blood samples were missing due to catheter failure; a summary of missing samples is provided in Table 1. Cortisol was higher in both groups after dehorning compared with sham (average increase of $2.6 \pm 7.00$ and $13.6 \pm 7.38 \mathrm{nmol} / \mathrm{L}$ for meloxicam and control, respectively; $P<0.01$ ), with a treatment $\times$ time interaction on d 0 (Figure $3 ; P=0.006$ ). At 24 h postdehorning, cortisol levels remained elevated from baseline values in both groups $(\mathrm{d}-130.8 \pm 2.66 \mathrm{nmol} / \mathrm{L}$, d $039.0 \pm 2.22$ $\mathrm{nmol} / \mathrm{L} ; P=0.01)$ There was no effect of environmental temperature on cortisol levels. Elevation in cortisol was significantly less for meloxicam calves from the time of dehorning $(0 \mathrm{~h})$ until $6 \mathrm{~h}$ after the procedure, but there was no difference between the treatment groups at 24 h (meloxicam $35.2 \pm 2.74$, control $34.8 \pm 3.64 \mathrm{nmol} / \mathrm{L}$; $P=0.13)$.

Heart rate was elevated over baseline for $24 \mathrm{~h}(\mathrm{~d}$ $-1108 \pm 1.8$, d $0109.4 \pm 2.4 \mathrm{bpm} ; P=0.03)$. Heart rates were higher, regardless of treatment, at $0 \mathrm{~h}$ than at all other time periods (Figure $4 ; P<0.004$ ), but there was no effect of time after $0 \mathrm{~h}(P=0.7)$. Overall, elevation in heart rates was less for meloxicam-treated calves after dehorning (increase meloxicam $3.74 \pm 0.96$, control $4.70 \pm 1.87 ; P=0.04)$. There was no effect of treatment over time. Heart rates were not significantly affected by environmental temperature.

There were no effects of age of calf, days since weaning, or weight on any of the traits measured.

\section{DISCUSSION}

The objectives were to add evidence to the body of work describing the duration of the stress response caused by dehorning, and to determine if administering meloxicam before dehorning alleviates that stress response. Because it is well established that dehorning surgery without a local anesthetic causes pain and an acute stress response (Petrie et al., 1996; Graf and Senn, 1999), all calves were given the local anesthetic lidocaine.

Respiratory and heart rates, as well as serum cortisol concentration, were all elevated after dehorning when compared with sham dehorning, regardless of treatment. This indicates that the dehorning surgery is stressful possibly for reasons other than pain, because all calves received lidocaine. Our experimental design controlled for stress of handling, but the technician who performed the actual dehorning was novel, as were the smoke and odors associated with cautery. It is also possible that in this case lidocaine did not completely eliminate pain. Previous studies have shown that $2 \%$ lidocaine can essentially eliminate the cortisol response to dehorning (McMeekan et al., 1998b; Grøndahl-Nielsen et al., 1999; Sutherland et al., 2002). However, in our study only a direct cornual nerve block, and not a ring block, was performed. It is possible that there were innervations to the horn by the supraorbital and infratrochlear nerves that arise from the frontal sinus and extend into the cavity of the horn in some calves (Habel, 1989) that were not blocked.

The duration of the stress response associated with dehorning appears to be at least $24 \mathrm{~h}$ because cortisol and heart rate were elevated in the meloxicam-treated group as well as the control group throughout the 24 
Table 1. Total number of calves for which blood samples were obtained at each time period ${ }^{1}$

\begin{tabular}{lcccccccc}
\hline & \multicolumn{8}{c}{ Time, $\mathrm{h}$} \\
\cline { 2 - 9 } Treatment & 0 & 0.5 & 1 & 1.5 & 2 & 4 & 6 & 24 \\
\hline Meloxicam & 60 & 60 & 60 & 58 & 58 & 57 & 58 & 60 \\
Placebo & 60 & 60 & 60 & 58 & 58 & 57 & 58 & 57 \\
\hline
\end{tabular}

${ }^{1}$ Two additional samples from each treatment at each time period were not included in the analysis due to malfunctioning of the gamma counter for 1 trial of 4 calves (trial 11).

$\mathrm{h}$ after dehorning. Cortisol in the meloxicam calves decreased after the first half hour. Because cortisol decreased while the calves were under local anesthesia and heart and respiratory rates remained elevated, it may be that heart and respiratory rates are actually more sensitive indicators of postsurgical pain, as well as stress and anxiety during inflammation, than cortisol, which may represent stress of handling or general discomfort.
When compared with controls, calves that received meloxicam had lower heart and respiratory rates after dehorning, as well as lower cortisol concentrations during $6 \mathrm{~h}$ after dehorning. Hence, our data support the hypothesis that meloxicam reduces distress caused by the dehorning surgery. In particular, respiratory rates for meloxicam-treated calves returned almost to baseline levels $2 \mathrm{~h}$ after dehorning and stayed there for the remainder of the trial. It is possible that variability

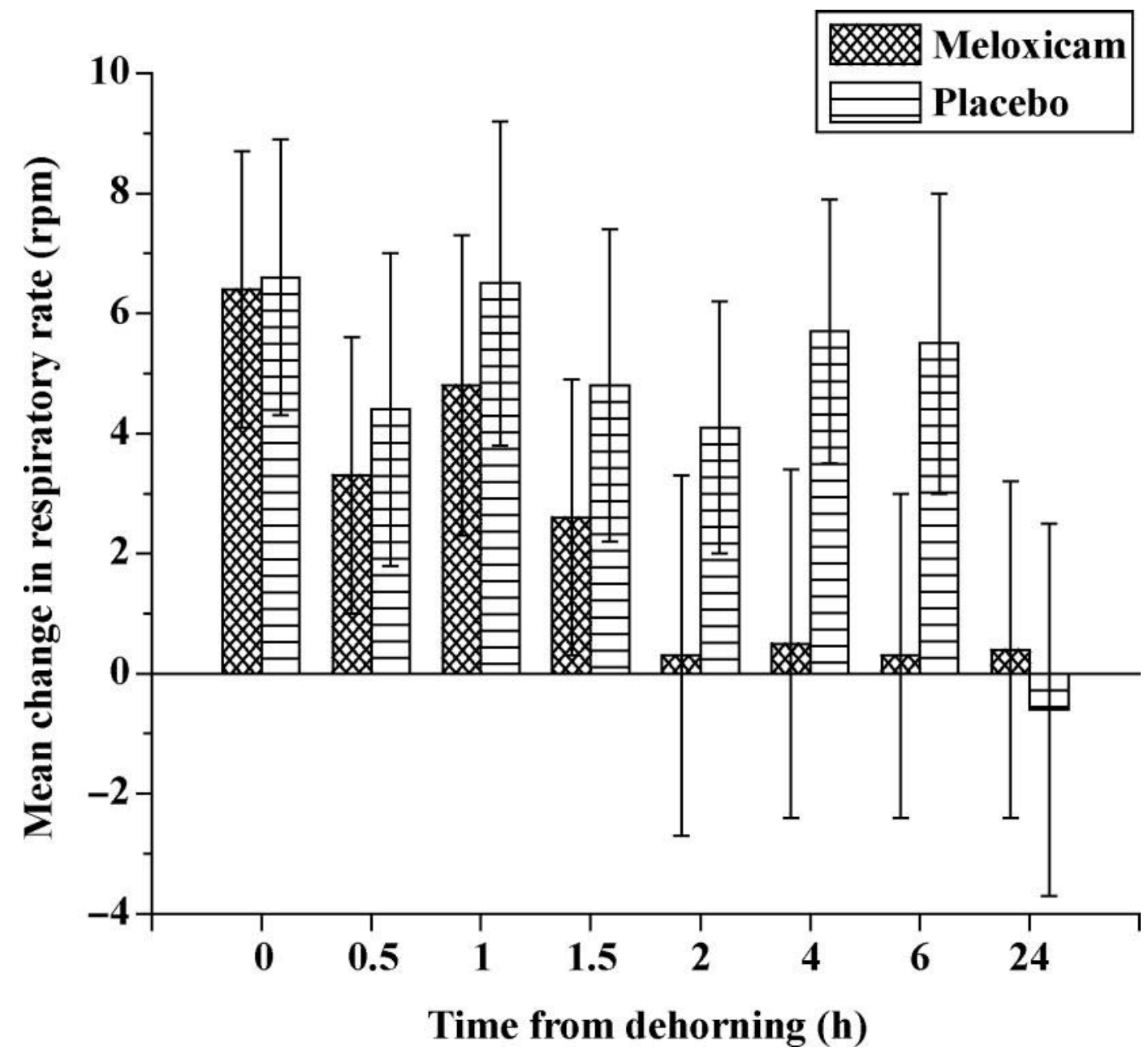

Figure 2. Mean $( \pm \mathrm{SE})$ change in respirations per minute $(\mathrm{rpm})$ between sham and actual dehorning. Increase in respiratory rate from d -1 to 0 was less in meloxicam-treated calves compared with placebo from 0 to $24 \mathrm{~h}(P=0.048)$. 


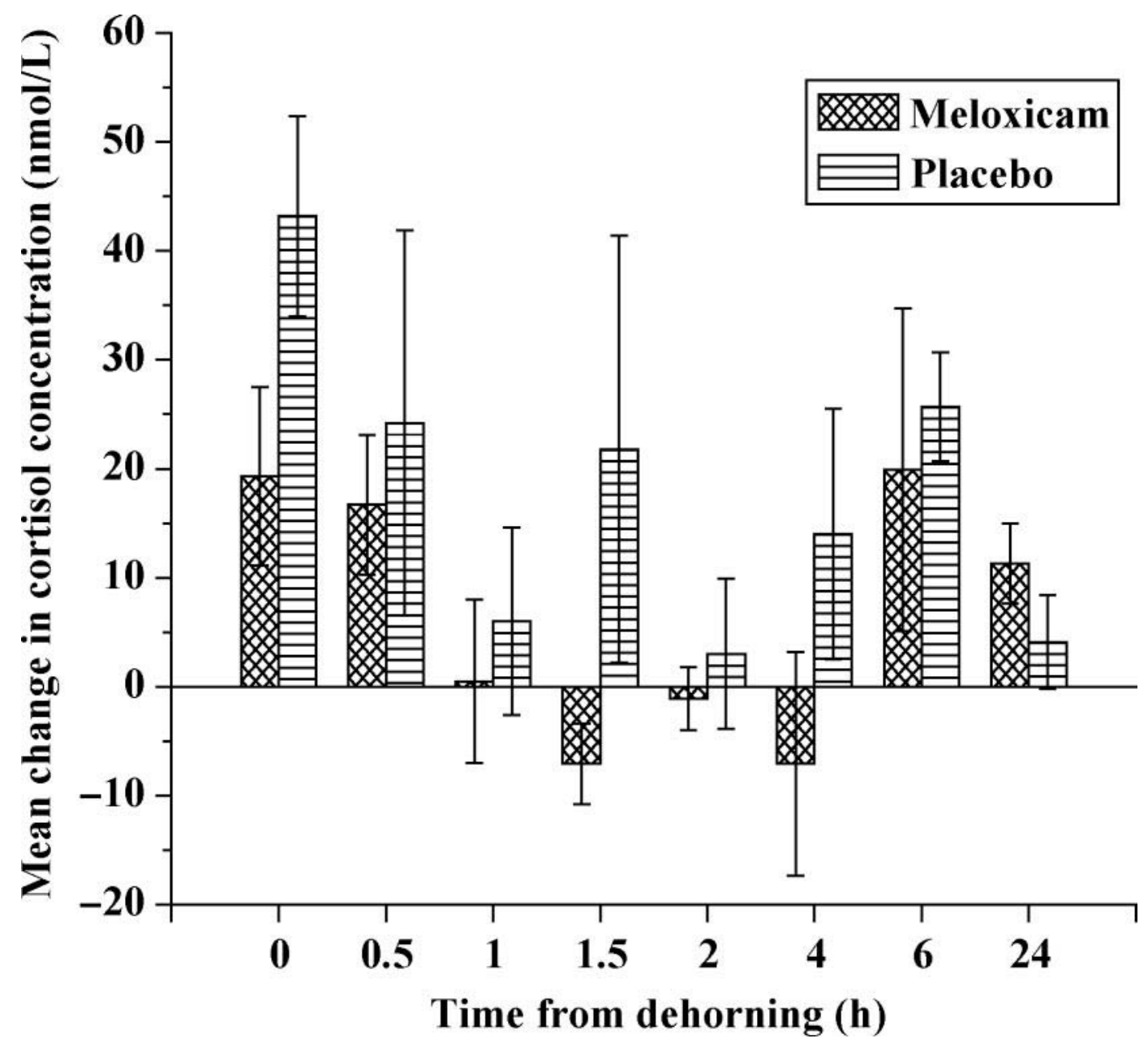

Figure 3. Mean $( \pm \mathrm{SE})$ change in serum cortisol concentration between sham and actual dehorning (treatment $\times$ time interaction, $P=$ 0.006). Increase in cortisol from $\mathrm{d}-1$ to 0 was less in meloxicam-treated calves from 0 to $6 \mathrm{~h}$. There was no treatment difference at $24 \mathrm{~h}$.

in the trait prevented this result from being statistically significant. Similarly, the cortisol results indicated that meloxicam conferred an immediate benefit. To our knowledge, there have been no other studies measuring respiratory rate after dehorning.

Heart rate was elevated in both groups at the time of dehorning and then dropped to a plateau by $0.5 \mathrm{~h}$, which was higher than rates after sham dehorning. Control calves plateaued at a higher level than meloxicam calves. This supports work by Grøndahl-Nielsen et al. (1999) who observed that heart rate was elevated for $3.5 \mathrm{~h}$ in dehorned calves receiving no anesthetic or analgesic compared with calves that were only sham dehorned. Heart rate was lower on $\mathrm{d}-1$ in the group of calves assigned to receive meloxicam. Because data were analyzed by assessing the change between $\mathrm{d}-1$ and $\mathrm{d} 0$, this discrepancy in baseline heart rate should not affect the results. It is possible that less fearful calves were inadvertently grouped in the meloxicam treatment, and these calves found restraint and handling generally less stressful. However, because the respiratory rates and cortisol concentration of these calves did not show the same pattern, this is unlikely explanation.

Ketoprofen-treated calves show a second peak in cortisol 5 to $6 \mathrm{~h}$ postdehorning when the NSAID wore off and pain resumed (Sutherland et al., 2002). Consequently, repeat doses of this drug are required for adequate postsurgical analgesia. In the present study, the effects of meloxicam were expected to wear off 26 $\mathrm{h}$ after administration, and we expected to see some rebound in serum cortisol at $24 \mathrm{~h}$ if it were to occur. Yet, the cortisol concentrations of the treatment groups were not different at $24 \mathrm{~h}$. This may indicate an end of the duration of pain, but behavioral data indicated a prolonged pain response to $44 \mathrm{~h}$ after dehorning (Heinrich, 2007). It is possible that the duration of action for meloxicam is longer in calves versus cows. Further analysis of the pharmacokinetics of meloxicam and a 


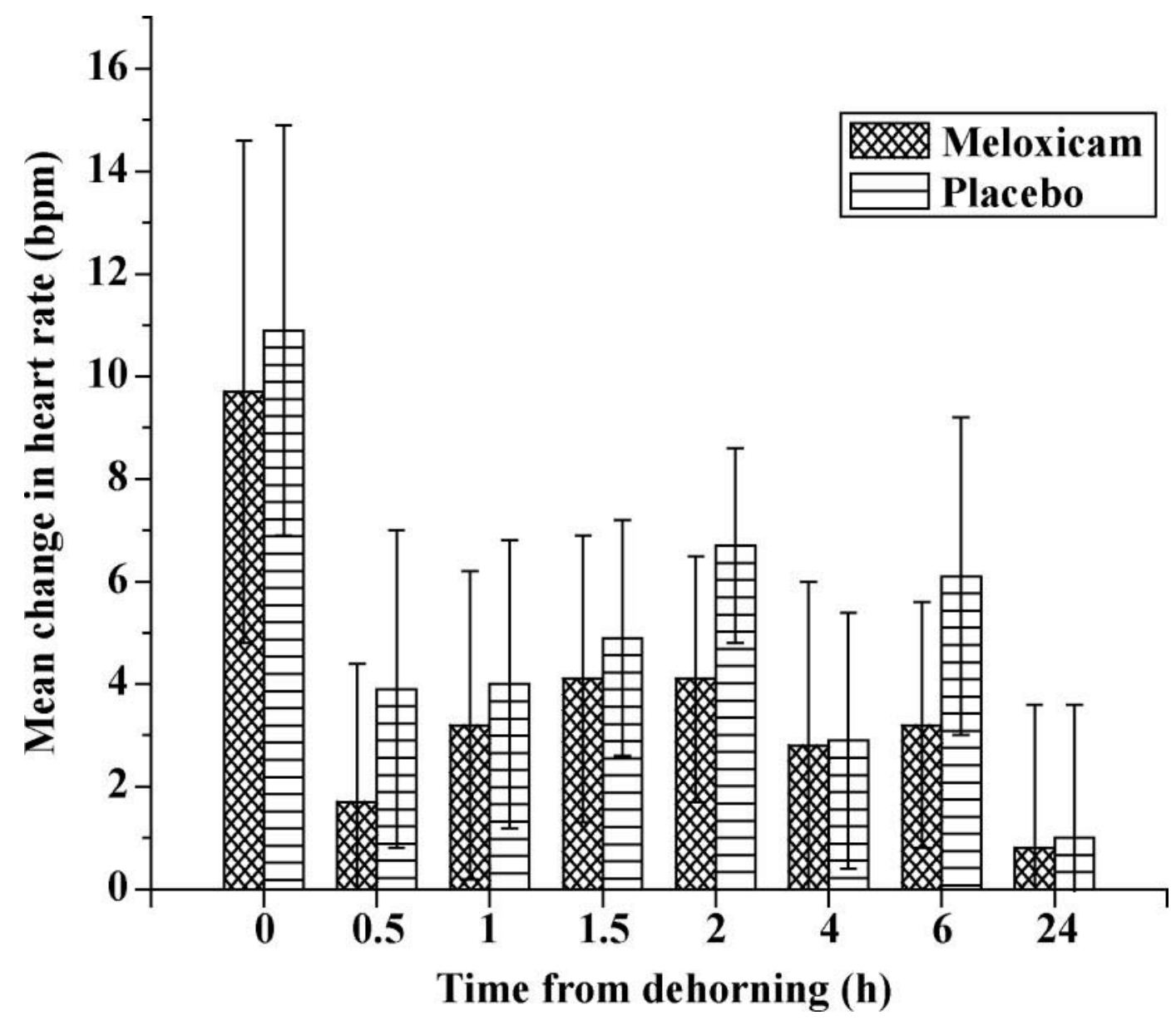

Figure 4. Mean [beats per minute $(\mathrm{bpm}) \pm \mathrm{SE}$ ] change in heart rate between sham and actual dehorning. Increase in heart rate from $\mathrm{d}-1$ to d 0 was less in meloxicam-treated calves compared with placebo from 0 to $24 \mathrm{~h}(P=0.04)$.

more detailed cortisol profile for the calf over 24 to 36 $\mathrm{h}$ is warranted.

An unexpected result was that meloxicam-treated calves had significantly lower serum cortisol than control calves immediately after dehorning (time $0 \mathrm{~h}$ ), while both groups were under local anesthesia (cornual nerve block). Studies involving ketoprofen found little to no benefit associated with giving ketoprofen alone (McMeekan et al., 1999; Millman et al., 2005). McMeekan et al. (1998b) and Sutherland et al. (2002) found no additional benefit for giving ketoprofen with a local anesthetic versus giving only local anesthetic during the duration of action of the local block. In the present study, meloxicam was administered $10 \mathrm{~min}$ before dehorning, so it is possible that the effect on cortisol was mediated through meloxicam. Pharmacokinetics assays of meloxicam in serum obtained from these calves support this hypothesis (data not shown).

Meloxicam is not currently approved for use in food animals in Canada or the United States. The half life of meloxicam is longer than that of flunixin meglumine
(Odensvik and Johansson, 1995); meloxicam could be considered preferable for use at dehorning because only 1 injection would be necessary, which would decrease cost and labor associated with provision of NSAID at dehorning.

Overall, these results suggest that cautery dehorning causes a stress response in calves lasting 6 to $24 \mathrm{~h}$, even when local anesthesia is used, and support the hypothesis that meloxicam reduces the stress response seen in changes in heart and respiratory rates and cortisol concentrations after dehorning. Because control calves, and not the meloxicam calves, exhibited the characteristic peak in cortisol at $1.5 \mathrm{~h}$ postdehorning when lidocaine was expected to wear off and the calves are assumed to be in pain, we conclude that meloxicam was effective at reducing the stress response due to pain.

\section{ACKNOWLEDGMENTS}

The authors thank Boehringer Ingelheim (Canada) Ltd. Vetmedica Division, Boehringer Ingelheim, Vet- 
medica, Germany, Ontario Ministry of Agriculture Food and Rural Affairs, National Science and Engineering Research Council, and Canadian Foundation for Innovation for funding. We are grateful to Shelly James, Laura Wright, and the staff at the Elora Dairy Research Centre for technical assistance, and to William Sears (University of Guelph) for statistical help. Melissa Sinclair (University of Guelph) kindly offered comments on an earlier draft of this work.

\section{REFERENCES}

Battaglia, D. F., J. M. Bowen, H. B. Krasa, L. A. Thrumi, C. Viguie, and F. J. Krash. 1997. Endotoxin inhibits the reproductive neuroendocrine axis while stimulating adrenal steroids: A simultaneous view from hypophyseal portal and peripheral blood. Endocrinology 138:158-163.

EMEA (European Agency for the Evaluation of Medicinal Products). 2007. Scientific discussion, Metacam. CVMP/323/97, London, UK.

Faulkner, P. M., and D. M. Weary. 2000. Reducing pain after dehorning in dairy calves. J. Dairy Sci. 83:2037-2041.

Gibson, T. J., C. B. Johnson, K. J. Stafford, S. L. Mitchinson, and D. J. Mellor. 2007. Validation of the acute electroencephalographic response of calves to noxious stimulus with scoop dehorning. N. Z. Vet. J. 55:152-157.

Graf, B., and M. Senn. 1999. Behavioural and physiological responses of calves to dehorning by heat cauterization with or without local anesthesia. Appl. Anim. Behav. Sci. 62:153-171.

Grøndahl-Nielsen, C., H. B. Simonsen, J. Damkjer Lund, and M. Hesselholt. 1999. Behavioural, endocrine and cardiac responses in young calves undergoing dehorning without and with the use of sedation and analgesia. Vet. J. 158:14-20.

Habel, R. E. 1989. Guide to the Dissection of Domestic Ruminants, 4th ed. Published by author, Ithaca, NY.

Heinrich, A. 2007. An investigation of meloxicam for the relief of pain associated with dehorning of dairy calves. Unpublished MSc Thesis. University of Guelph, Guelph, Ontario, Canada.

Landoni, M. F., F. M. Cunningham, and P. Lees. 1995. Pharmacokinetics and pharmacodynamics of ketoprofen in calves applying PK/PD modeling. J. Vet. Pharmacol. Ther. 18:315-324.

McMeekan, C. M., D. J. Mellor, K. J. Stafford, R. A. Bruce, R. N. Ward, and N. G. Gregory. 1998a. Effects of local anesthesia of 4 to 8 hours' duration on the acute cortisol response to scoop dehorning in calves. Aust. Vet. J. 76:281-285.

McMeekan, C. M., K. J. Stafford, D. J. Mellor, R. A. Bruce, R. N. Ward, and N. G. Gregory. 1998b. Effects of regional analgesia and/ or a non-steroidal anti-inflammatory analgesic on the acute cortisol response to dehorning in calves. Res. Vet. Sci. 64:147-150.

McMeekan, C. M., K. J. Stafford, D. J. Mellor, R. A. Bruce, R. N. Ward, and N. G. Gregory. 1999. Effects of local anesthetic and a non-steroidal anti-inflammatory analgesic on the behavioural responses of calves to dehorning. NZ Vet. J. 47:92-96.

Mellema, S. C., M. G. Doherr, B. Wechsler, S. Thüer, and A. Steiner. 2006. Influence of local anesthesia on pain and distress induced by two bloodless castration methods in young lambs. Vet. J. $172: 274-283$.

Milligan, B. N., T. Duffield, and K. Lissemore. 2004. The utility of ketoprofen for alleviating pain following dehorning in young dairy calves. Can. Vet. J. 45:140-143.

Millman, S. T., T. Duffield, K. Lissemore, S. James, and L. Misch. 2005. Does ketoprofen alleviate acute pain in young calves during dehorning? J. Anim. Sci. 83(Suppl. 1): 374-375. (Abstr.)

Odensvik, K., and I. M. Johansson. 1995. High-performance liquid chromatography method for determination of flunixin in bovine plasma and pharmacokinetics after single and repeated doses of the drug. Am. J. Vet. Res. 56:489-495.

Paull, D. R., C. Lee, I. G. Colditz, S. J. Atkinson, and A. D. Fisher. 2007. The effect of a topical anesthetic formulation, systemic flunixin and carprofen singly or in combination, on cortisol and behavioural responses of Merino lambs to mulesing. Aust. Vet. J. 85:98-106.

Petrie, N. J., D. J. Mellor, K. J. Stafford, R. A. Bruce, and R. N. Ward. 1996. Cortisol responses of calves to two methods of disbudding used with or without local anaesthetic. N. Z. Vet. J. 44:9-14.

Plumb, D. C. 2002. Veterinary Drug Handbook. 4th ed. Iowa State University Press, Ames.

Stafford, K. J., and D. J. Mellor. 2005. Dehorning and disbudding distress and its alleviation in calves. Vet. J. 169:337-349.

Stafford, K. J., D. J. Mellor, S. E. Todd, R. N. Ward, and C. M. McMeekan. 2003. The effect of different combinations of lignocaine, ketoprofen, xylazine and tolazoline on the acute cortisol response to dehorning in calves. N. Z. Vet. J. 51:219-226.

Stewart, M., K. J. Stafford, S. K. Dowling, A. L. Schaefer, and J. R. Webster. 2008. Eye temperature and heart rate variability of calves disbudded with or without local anesthetic. Physiol. \& Behav. 93:789-797.

Sutherland, M. A., D. J. Mellor, K. J. Stafford, N. G. Gregory, R. A. Bruce, and R. N. Ward. 2002. Cortisol responses to dehorning of calves given a 5-h local anaesthetic regimen plus phenylbutazone, ketoprofen or adrenocorticotropic hormone prior to dehorning. Res. Vet. Sci. 73:115-123.

Sylvester, S. P., K. J. Stafford, D. J. Mellor, R. A. Bruce, and R. N. Ward. 2004. Behavioural responses of calves to amputation dehorning with and without local anaesthesia. Aust. Vet. J. 82:697-700.

Thüer, S., S. Mellema, M. G. Doherr, B. Wechsler, K. Nuss, and A. Steiner. 2007. Effect of local anesthesia on short- and long-term pain induced by two bloodless castration methods in calves. Vet. J. $173: 333-342$.

Weary, D. M., L. Neil, F. C. Flower, and D. Fraser. 2006. Identifying and preventing pain in animals. Appl. Anim. Behav. Sci. 100:6476.

Woodbury, M. R., N. A. Caulkett, and P. R. Wilson. 2002. Comparison of lidocaine and compression for velvet antler analgesia in wapiti. Can. Vet. J. 43:869-875. 